\title{
Primary Esophageal Lymphoma: A Rare Entity
}

\author{
Sanjeev Sachdeva Arpan Jain Ashok Dalal A.S. Puri \\ Department of Gastroenterology, GB Pant Hospital, New Delhi, India
}

\section{Keywords}

Primary esophageal lymphoma $\cdot$ Rare entity . Immunohistochemistry

\section{Linfoma esofágico primário: uma entidade rara}

\section{Palavras Chave}

Primário esofágico linfoma - Entidade rara .

Imunohistoquímica

A 46-year-old man presented with progressive dysphagia (to both solids and liquids), retrosternal chest pain, and low backache for 8 months. He also complained of significant weight loss and anorexia. There was no history of chronic or new medication use, consumption of tobacco or alcohol, and there were no comorbidities. His physical examination was normal except for mild tenderness in the sacral region. Laboratory results and chest Xray were normal. Serology for HIV was negative. Upper gastrointestinal endoscopy revealed an ulcero-proliferative growth in the esophagus starting at $25 \mathrm{~cm}$ from incisors and resulting in stricture (Fig. 1a, arrow). The stricture was tight and irregular and was not transposable by the endoscope, hence the stomach could not be evaluated. Histopathological examination of biopsies taken from the lesion showed infiltration with sheets of atypical lymphoid cells with scattered mitotic figures suggestive of lymphoma (Fig. 2a, arrows). Immunohistochemistry (IHC) showed diffuse positivity for CD-20 and MUM-1 (Fig. 2b, c) and negativity for CD-3 and CD-23, suggesting the diagnosis of diffuse large B-cell type non-Hodgkin's lymphoma. Contrast-enhanced abdominopelvic and chest computed tomography (CT) scan showed long
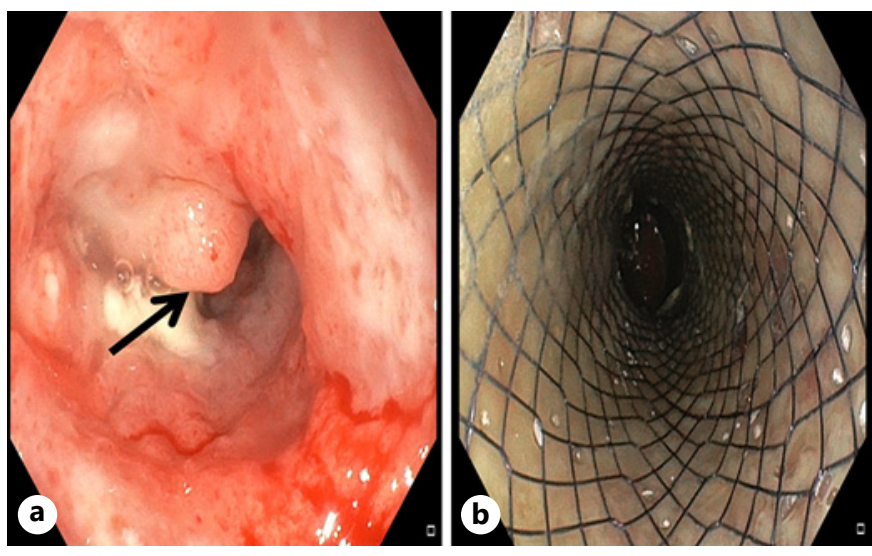

Fig. 1. a Endoscopy showing ulcero-proliferative growth (arrow) in the esophagus resulting in stricture. b A self-expandable esophageal metal stent placed across the esophageal growth. karger@karger.com www.karger.com/pjg

Karger $\stackrel{\text { ' }}{5}$

BOPEN ACCESS
(C) 2021 Sociedade Portuguesa de Gastrenterologia. Published by S. Karger AG, Basel

This is an Open Access article licensed under the Creative Common Attribution-NonCommercial-4.0 International License (CC BY-NC) (http://www.karger.com/Services/OpenAccessLicense), applicable to the online version of the article only. Usage and distribution for commercial purposes requires written permission. 
Fig. 2. a Histopathological examination showing infiltration with sheets of atypical lymphoid cells (arrows) with scattered mitotic figures suggestive of lymphoma. b IHC showing diffuse positivity for CD20. c IHC showing positivity for MUM-1.

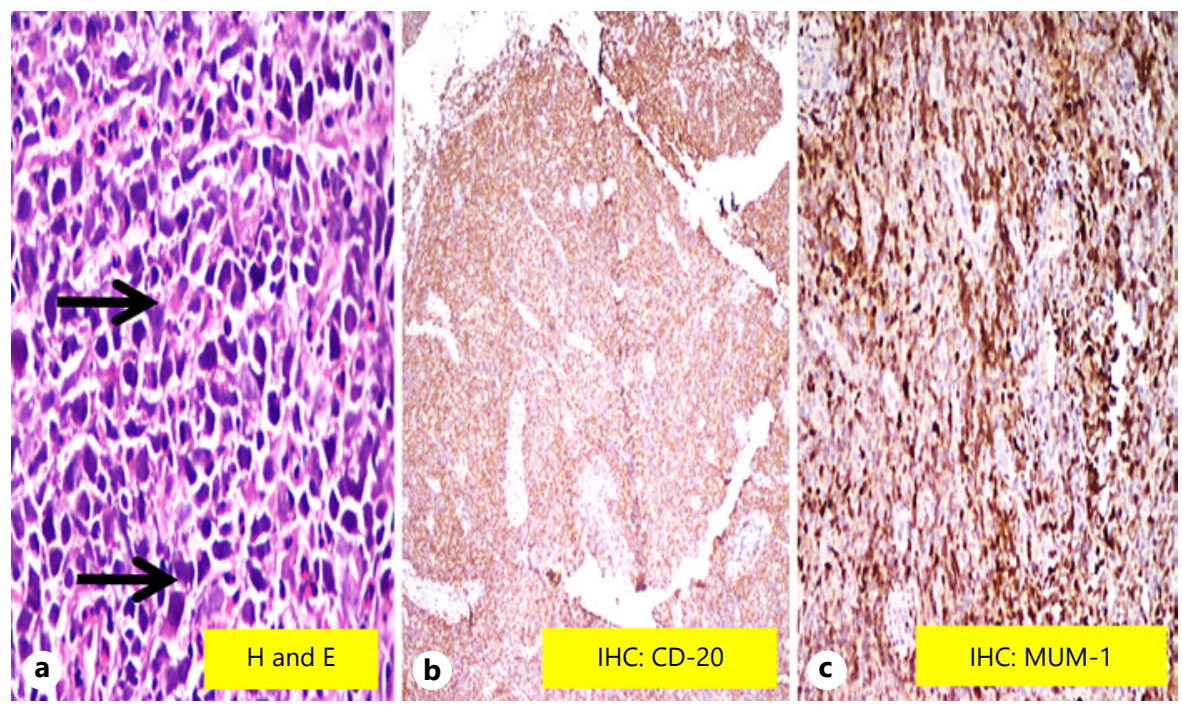

Fig. 3. a, b CT scan showing circumferential thickening (arrow) involving the distal $15 \mathrm{~cm}$ of the esophagus and sacral metastasis (arrowhead). c Magnetic resonance imaging scan showing sacral metastasis (arrowhead).

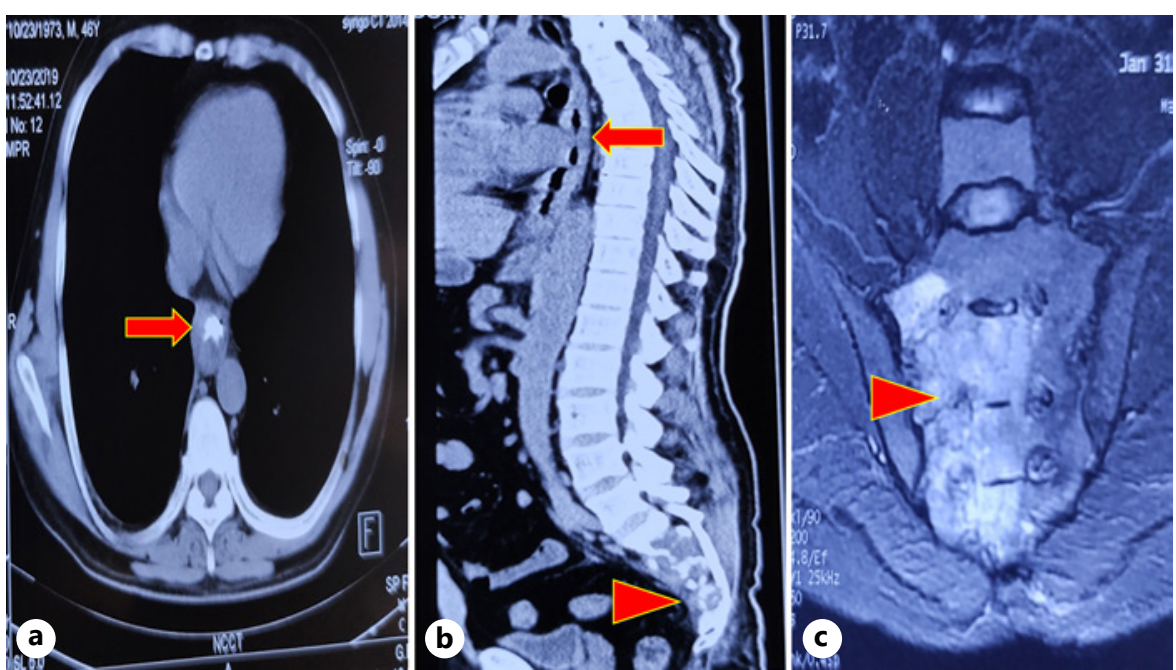

segment circumferential thickening involving the distal $15 \mathrm{~cm}$ of the esophagus (Fig. 3a, b, arrow) with few small para-esophageal lymph nodes, and lytic lesions involving S1-S3 vertebrae suggestive of metastases (Fig. 3b, arrowhead). Magnetic resonance imaging of the spine also showed lytic lesions in the sacrum (Fig. 3c, arrowhead). Positron emission tomography with CT and bone marrow biopsy from the sacral region confirmed metastasis. Since dysphagia was severe, a self-expandable fully covered $18 \mathrm{~mm} \times 150 \mathrm{~mm}$ esophageal metal stent was placed for palliation (Fig. 1b), and the patient was referred to the Oncology Department where he received R-CHOP (rituximab-cyclophosphamide, doxorubicin, vincristine, and prednisone) regimen. He also received external beam radiotherapy for sacral metastasis. His dysphagia improved and oral intake was satisfactory on follow-up at 8 weeks.

The esophagus represents a rare location of primary gastrointestinal lymphoma, and lymphoma accounts for less than $1 \%$ of all esophageal malignancies $[1,2]$. Endoscopic mucosal resection has higher sensitivity than routine endoscopic pinch biopsies. Management usually involves chemotherapy, radiation, surgery, or a combination approach [3]. IHC in addition to conventional histopathology is important in establishing the diagnosis of this unusual malignancy [4]. 


\section{Statement of Ethics}

Written informed consent was obtained from the patient for publication of this case report and any accompanying images.

\section{Conflict of Interest Statement}

The authors have no conflicts of interest to declare.
Funding Sources

The authors have no funding sources to declare.

\section{Author Contributions}

Sanjeev Sachdeva: Acquisition of data; analysis and interpretation of data; drafting of the manuscript. Arpan Jain: Acquisition of data; revision of the manuscript for important intellectual content. Ashok Dalal: Acquisition of data; revision of the manuscript for important intellectual content. A.S. Puri: Acquisition of data; critical revision of the manuscript.

\section{References}

1 Inayat F, Munir A, Wahab A, Younus F, Zafar F, Ullah W. Primary Esophageal Diffuse Large B-Cell Lymphoma: A Comparative Review of 15 Cases. J Investig Med High Impact Case Rep. 2018 Jan-Dec;6:2324709618820887.
2 Ghimire P, Wu GY, Zhu L. Primary esophageal lymphoma in immunocompetent patients: two case reports and literature review. World J Radiol. 2010 Aug;2(8):334-8.

3 Sabljak P, Stojakov D, Bjelovic M, Mihaljevic B, Velickovic D, Ebrahimi K, et al. Primary esophageal diffuse large B-cell lymphoma: report of a case. Surg Today. 2008;38(7):647-50.
4 Wu N, Pang L, Chen Z, Wang Y, Ma Q, Chen $\mathrm{G}$, et al. Primary esophageal CD30-positive ALK-positive anaplastic large cell lymphoma: a case report and literature review. J Gastrointest Cancer. 2011 Mar;42(1):57-60. 